\title{
Differences between umbilical blood gas in term and preterm newborns
}

\author{
Maria Luisa Tataranno ${ }^{1}$, Giuseppe De Bernardo ${ }^{2}$, Daniele Trevisanuto ${ }^{3}$, Desiree Sordino ${ }^{2}$, Marina Riccitelli ${ }^{4}$, \\ Giuseppe Buonocore ${ }^{5}$, Serafina Perrone ${ }^{6}$
}

\author{
${ }^{1} \mathrm{MD}, \mathrm{PhD}$, Department of Neonatology, and Brain Center Rudolf Magnus, University Medical Center Utrecht, \\ Utrecht University, Utrecht, The Netherlands \\ ${ }^{2}$ MD, Department of Mother's and Child's Health, Poliambulanza Foundation Hospital Institute, Brescia, Italy \\ ${ }^{3}$ MD, Associate Professor, Department of Women's and Children's Health, University of Padua, Azienda \\ Ospedaliera di Padova, Padua, Italy \\ ${ }^{4} \mathrm{MD}$, Department of Molecular and Developmental Medicine, University of Siena, Siena, Italy \\ ${ }^{5}$ MD, Full Professor of Pediatrics, Department of Molecular and Developmental Medicine, University of Siena, \\ Siena, Italy \\ ${ }^{6} \mathrm{MD}, \mathrm{PhD}$, Department of Molecular and Developmental Medicine, University of Siena, Siena, Italy
}

\section{Type of article: Original}

\begin{abstract}
Introduction: Cord blood gas analysis reflects placental respiratory and metabolic function and is commonly used to assess fetal status at birth. Our aim was to identify the differences in blood gas parameters between the umbilical artery (UA) and umbilical vein (UV) in term and preterm infants.

Methods: This was a prospective pilot study. Umbilical cord artery and UV samples were consecutively collected from 225 term and 57 preterm infants at the University Hospital of Padua and at the neonatal unit of Ruesch Hospital in Naples, Italy. Blood gas-analysis and glucose measurement were performed in all samples. Term infants were divided into adequate for gestational age (AGA) and small for gestational age (SGA) according to birth weight percentile. Data were analyzed using Pearson Product-Moment Correlation, independent-samples t-test, and paired-samples t-test. A p-value $<0.05$ was considered statistically significant.

Results: The median gestational age of preterm and term newborns were 34 weeks $( \pm 2)$ and 39 weeks $( \pm 1)$ respectively. The $\mathrm{pH}, \mathrm{pO}_{2}$, were lower and $\mathrm{pCO}_{2}, \mathrm{HCO}_{3}{ }^{-}$and base excess (BE) were higher in the UA compared with the UV, in both AGA and SGA term infants. In preterm infants, no statistically significant differences were found between the UA and UV regarding $\mathrm{pH}$, while the $\mathrm{pO}_{2}$ was lower and $\mathrm{pCO}_{2}$ was higher in the UA than UV (respectively: 22.5 vs. 32.4 and 53.1 vs. 42.8 ; $\mathrm{p}<0.0001$ ). In the $\mathrm{UA}, \mathrm{pO}_{2}, \mathrm{BE}$ and potassium $\left(\mathrm{K}^{+}\right)$were lower (respectively: 22.5 vs. $25.1 ;-2.5$ vs. $-3.7 ; 4.8$ vs. $5.8 ; \mathrm{p}<0.001)$ while sodium $\left(\mathrm{Na}^{+}\right)$and calcium $\left(\mathrm{Ca}^{++}\right)$were higher in preterm than term newborns (respectively: 135.7 vs. $133.6 ; \mathrm{p}<0.001 ; 1.4$ vs. $1.3 ; \mathrm{p}<0.001$ ). Glycaemia was lower in the UA than in the UV in all newborns (respectively: 66 vs. 77 in AGA term newborns; 63 vs. 71 in SGA term newborns; 68 vs. 76 in preterm newborns; $p<0.0001)$ and was related to venous glycaemia measured in the first hour of life $(n=282, r=0.60 ; p<0.001)$.

Conclusions: Significant differences in blood gas parameters between the UA and UV in term and preterm newborns suggest the importance of the placental barrier and the need for accurate cord blood gas analysis interpretation at birth. UA and UV samples at birth are required to assess with higher accuracy the metabolic status of the newborn in utero. Further studies are needed to evaluate if cord glycemic values could be a noninvasive tool for prediction of glycaemia during the first hour of life.
\end{abstract}

Keywords: Blood gas analysis, Cord blood, Newborn infants, Oxygenation, Metabolism

\section{Corresponding author:}

Dr. Serafina Perrone, Neonatal Care Unit, Department of Molecular and Developmental Medicine, University Hospital of Siena, Viale M. Bracci 16, 53100 Siena, Italy. Telephone: +39-0577-586542, Fax: +39-0577-586182, Email: saraspv@yahoo.it

Received: August 17, 2018, Accepted: January 26, 2019, Published: June 2019

iThenticate screening: February 08, 2019, English editing: March 28, 2019, Quality control: April 08, 2019

This article has been reviewed / commented by four experts

(C) 2019 The Authors. This is an open access article under the terms of the Creative Commons Attribution-NonCommercialNoDerivs License, which permits use and distribution in any medium, provided the original work is properly cited, the use is non-commercial and no modifications or adaptations are made. 


\section{Abbreviations / Acronyms:}

AGA: Adequate for Gestational Age; BE: Base Excess; GA: Gestational Age; IR: Interquartile Range; SGA: Small for Gestational Age; UA: Umbilical Artery; UV: Umbilical Vein

\section{Introduction}

Preterm birth, defined as delivery prior to 37 weeks of gestation, is the leading cause of perinatal and neonatal mortality and morbidity. Worldwide, preterm birth affects 15 million children every year, representing about $10 \%$ of births, and contributes to more than $50 \%$ of neonatal deaths $(1,2)$. Preterm infants are metabolically immature and prone to various diseases linked to early birth. Common morbidities include respiratory complications, hypoglycemia, temperature instability, hyperbilirubinemia, circulatory and hemodynamic compromise and neurodevelopmental delays. The fetal circulation is an entirely transient event, not replicated at any point in later life, and functionally distinct from the pediatric and adult circulations. The central unique feature of the fetal circulation is that gas exchange occurs not in the lungs, but via the placenta. Oxygenated blood returns to the fetus from the placenta via a single umbilical vein (UV) (3). Understanding the physiology of the fetal circulation is vital for accurate interpretation of fetal assessments in utero and for later management of term and preterm newborns. There is growing interest in performing umbilical cord blood gas analysis to obtain metabolic information about neonates and their mothers (4-6). The UV reflects maternal status and placental function, while the umbilical artery (UA) reflects fetal oxygenation and acid - base status (4). Moreover, arteriovenous oxygen differences reflect placental respiratory function independently from gestational age (GA), birth weight, duration of labor, and mode of delivery (7). Therefore, for early and accurate detection of the health status of newborns, a complete approach would include both the UA and UV sampling. Studies on differences between UA and UV pH showed that $\mathrm{pH}$, measured in the UA can give valuable information and is useful in predicting the neonatal outcome in term infants $(8,9)$. There is a lack of evidence reporting differences between UA and UV in preterm newborns. Moreover, differences in biochemical parameters between UA and UV are not investigated yet in term infants born appropriate for gestational age (AGA) or small for gestational age (SGA).

The present study was designed to fulfill these gaps in the knowledge, investigating the metabolic differences between the UA and UV gas analysis both in term and in preterm infants. The second objective of the study was to investigate the relation between venous glycemic levels at one hour after birth and glucose levels in both the UA and UV. Glucose is the main source of energy for organ function in neonates, and neonatal hypoglycemia may cause severe neurological damages. Tight glycemic control is recommended to identify neonates at risk. Previous, noninvasive, blood glucose monitoring systems have been unsuccessful in neonates; and there is a need for more accurate and less invasive methods for glycemic measurement in this population (9). Recent studies have shown that the cord blood glucose levels are significantly associated with maternal blood glucose levels at delivery (10).

\section{Material and Methods}

\subsection{Research design and patients}

A total of 282 infants born between January 2014 and September 2015 in two Italian centers, the University Hospital of Padua and the C.G. Ruesch Hospital of Naples, were progressively enrolled in this cross-sectional pilot study. In total, 225 infants were born at term [mean gestational age (GA): $39 \pm 1$ weeks] and 57 were born preterm (mean GA: $34 \pm 2$ weeks). Term newborns were divided into AGA and SGA according to national growth charts.

\subsection{Selection criteria}

\subsubsection{Inclusion criteria}

Neonates born from spontaneous vaginal delivery, with normal progression of labor and infants born from elective cesarean section for maternal request were included in the study.

\subsubsection{Exclusion criteria}

Neonates born from mothers with hypertensive disorders, maternal diabetes, or placental abruption, and those with fetal malformations, chromosomal abnormality, metabolic disorders, or clinical signs of maternal or fetal infection were excluded.

\subsection{Blood sampling and measures}

Blood samples were collected from the umbilical cord from both artery and vein from a double-clamped cord, after at least 60 seconds following delivery (11). This method (delayed cord clamping) is the standard of care procedure at the Ruesch Hospital and at the University Hospital of Padua. Only nurses or midwifes, who were skilled in blood sampling, performed this procedure in a standardized way. Samples were collected within 20 minutes after delivery, 
using heparinized 5-ml syringes. Samples were analyzed within 5-10 minutes after sampling using the IRMA TRUPOINT ${ }^{\circledR}$ Blood Analysis System System with CC type cartridges (Minneapolis, MN, USA) following already published guidelines for cord blood sampling (12). The analyzer allows testing of $\mathrm{pH}$. $\mathrm{pCO}_{2}, \mathrm{pO}_{2}, \mathrm{Na}^{+}, \mathrm{K}^{+}, \mathrm{Ca}^{++}$, hematocrit (Htc), $\mathrm{HCO}^{-}, \mathrm{BE}$. Blood glucose measurement was performed in cord blood and at 1 hour of life by heel prick using StatStrip Xpress (Nova Biomedical) glucometer [10-900 mg/dL (1-50 mmol/L)].

\subsection{Statistical analysis}

Differences between arterial and venous $\mathrm{pH}, \mathrm{pO}_{2}, \mathrm{pCO}_{2}$, base excess $(\mathrm{BE})$, bicarbonate $\left(\mathrm{HCO}_{3}-\right)$, hematocrit, glucose, and electrolytes (sodium $[\mathrm{Na}]$, potassium [K], calcium [Ca]) were calculated as the absolute differences between the artery and vein (delta). Data were presented as mean \pm standard deviation (SD) and medians \pm interquartile range (IR) where appropriate. The paired t-test was used to determine differences between the UA and $\mathrm{UV}$ in all groups (term AGA, term SGA, and preterm infants). The unpaired t-test was used to analyze the differences among groups for arterial and venous cord blood gas analysis independently. Pearson's correlation analysis was used to identify correlations between glycemic values of the artery and vein. Linear regression was used to establish relations between cord blood glycemic values and glycaemia during the first hour of life. A p value less than 0.05 was considered significant. Results were presented using bar graphs, box-plots, and dot-plots where appropriate. Statistical analyses were performed using the IBMC SPSSC Statistics version 21 (IBMC Corp., Armonk, NY, USA).

\subsection{Ethics of research}

Written informed consent was obtained from the parents of enrolled infants. Written informed consent was obtained from the parents of enrolled infants. Research was conducted following the Helsinki-Ethical Principles for Medical Research Involving Human Subjects.

\section{Results}

Patients' clinical characteristics are shown in Table 1. None of the neonates showed clinical signs of perinatal asphyxia or hypoxia.

Table 1. Clinical characteristics of the population

\begin{tabular}{|l|l|l|l|}
\hline Variables & $\begin{array}{l}\text { Term AGA newborns } \\
(\mathrm{n}=194)\end{array}$ & $\begin{array}{l}\text { Term SGA newborns } \\
(\mathrm{n}=31)\end{array}$ & $\begin{array}{l}\text { Preterm newborns } \\
(\mathrm{n}=57)\end{array}$ \\
\hline Gestational age (week); mean (SD) & $39(1)^{1}$ & $38(1)$ & $34(2)^{1}$ \\
\hline Birth weight (gram); mean (SD) & $3340(380)^{3}$ & $2593(217)^{3}$ & $2267(566)^{3}$ \\
\hline $\begin{array}{l}\text { Median of 1-minute Apgar score }\left(5^{\text {th }}-\right. \\
\text { 95 }\end{array}$ & $8(8-9)$ & $8(8-9)$ & $8(8-8)^{1,2}$ \\
\hline $\begin{array}{l}\text { Median of 5-minute Apgar score }\left(5^{\text {th }}-\right. \\
\text { 95 }\end{array}$ & $9(9-10)$ & $9(9-10)$ & $9(9-9)^{1,2}$ \\
\hline Length (cm) & $49.8(1.6)^{3}$ & $47.0(1.2)^{3}$ & $44.3(3.6)^{3}$ \\
\hline Head Circumference (cm) & $35.0(1.4)^{3}$ & $33.3(1.3)^{3}$ & $31.8(2.2)^{3}$ \\
\hline Gender (m/f) & $105 / 89^{\circ}$ & $9 / 22^{\circ}$ & $30 / 27$ \\
\hline Type of delivery (SVD/CS) & $54 / 140$ & $4 / 27$ & $12 / 45$ \\
\hline Smoker mother (yes/no) & $48 / 146$ & $12 / 19^{2}$ & $5 / 52^{2}$ \\
\hline AGA/SGA & $194 / 0$ & $0 / 31$ & $43 / 13$ \\
\hline
\end{tabular}

AGA; Adequate for gestational age; SGA: Small for gestational age; $1: \mathrm{p}<0.01$, versus AGA term infants and preterm infants; $2: \mathrm{p}<0.01$, versus SGA term infants and preterm infants; $3: \mathrm{p}<0.01$, among the three groups

\subsection{Differences in cord blood biochemical parameters between the UA and UV in all groups}

According to t-test for paired data, the $\mathrm{pO}_{2}$ was higher, and $\mathrm{pCO}_{2}$ and $\mathrm{HCO}_{3}{ }^{-}$were significantly lower in the UV compared with the UA in all of the groups $(\mathrm{p}<0.001$ (Table 2$)$. The $\mathrm{pH}$ was significantly higher in the UV than in the UA in term AGA and SGA infants ( $\mathrm{p}=0.003$ and $\mathrm{p}<0.000$, respectively), but not in preterm infants. Pairedsamples t-test and independent-samples t-test revealed that BE was significantly higher in the UA than in the UV of AGA infants ( $p=0.003$ ), but not in SGA and preterm infants. Glucose was significantly higher in the UV than in the UA among all groups $(p<0.001)$. According to the independent-samples t-test and paired-samples t-test, hematocrit was significantly higher in the UV than in the UA in term AGA and preterm infants ( $p=0.002$ and $p=0.009$ ), but not in SGA infants. $\mathrm{Na}^{+}$values in the UV were higher than those in the UA of AGA and SGA term infants $(\mathrm{p}<0.001$ and 
$\mathrm{p}=0.009$ respectively, paired-samples t-test). $\mathrm{K}^{+}$values were not significantly different between the UA and UV in all groups. Arterial $\mathrm{Ca}^{++}$values were significantly lower in the UA than in the UV only in AGA term infants $(\mathrm{p}<0.001$, paired-samples t-test). According to the Pearson Product-Moment Correlation analysis, significant linear correlation was found in glucose values between UA and venous glycaemia in the first hour after birth in AGA term infants (Figure 1, Pearson's correlation coefficient: 0.6, $\mathrm{p}<0.001$ ). There was no correlation between the UA pH and $\mathrm{UV} \mathrm{pH}$ in AGA term infants.

Table 2. Cord blood biochemical parameters between the UA and UV in all groups

\begin{tabular}{|c|c|c|c|c|c|c|c|c|c|}
\hline \multirow[t]{2}{*}{ Variables } & \multicolumn{3}{|c|}{ Term AGA $(n=194)$} & \multicolumn{3}{|c|}{ Term SGA $(n=31)$} & \multicolumn{3}{|c|}{ Preterm $(\mathrm{n}=57)$} \\
\hline & Artery & Vein & $p$-value & Artery & Vein & p-value & Artery & Vein & p-value \\
\hline $\mathrm{pH} ;$ Mean \pm SD & $7.22 \pm 0.52$ & $7.33 \pm 0.07$ & 0.003 & $7.27 \pm 0.07$ & $7.35 \pm 0.08$ & 0.000 & $7,28 \pm 0.08$ & $7.29 \pm 0.38$ & 0.804 \\
\hline $\mathrm{pCO}_{2} ;$ Mean \pm SD & $53.0 \pm 10.4$ & $43.0 \pm 8.4$ & 0.000 & $50.3 \pm 8.7$ & $40.2 \pm 9.3$ & 0.000 & $53.1 \pm 10.6$ & $42.8 \pm 9.3$ & 0.000 \\
\hline $\mathrm{pO}_{2} ;$ Mean \pm SD & $25.1 \pm 8.6$ & $36.6 \pm 12.1$ & 0.000 & $23.9 \pm 4.4$ & $36.7 \pm 9.5$ & 0.000 & $22.5 \pm 5.7$ & $32.4 \pm 8.4$ & 0.000 \\
\hline $\mathrm{BE} ; \mathrm{Mean} \pm \mathrm{SD}$ & $-3.7 \pm 2.9$ & $-3.3 \pm 2.5$ & 0.003 & $-4.3 \pm 2.5$ & $-3.6 \pm 2.3$ & 0.055 & $-2.5 \pm 2.6$ & $-3.0 \pm 2.6$ & 0.081 \\
\hline $\mathrm{Na}^{+} ; \mathrm{Mean} \pm \mathrm{SD}$ & $133.6 \pm 5.7$ & $135.4 \pm 5.2$ & 0.000 & $134.7 \pm 4.6$ & $136.6 \pm 3.8$ & 0.035 & $135.7 \pm 3.0$ & $135.4 \pm 2.9$ & 0.326 \\
\hline $\mathrm{Ca}^{++} ; \mathrm{Mean} \pm \mathrm{SD}$ & $1.3 \pm 0.7$ & $1.3 \pm 0.1$ & 0.000 & $1.2 \pm 0.2$ & $1.3 \pm 0.1$ & 0.120 & $1.4 \pm 0.1$ & $1.4 \pm 0.1$ & 0.117 \\
\hline $\mathrm{K}^{+} ;$Mean $\pm \mathrm{SD}$ & $5.8 \pm 1.4$ & $5.7 \pm 1.6$ & 0.661 & $6.2 \pm 1.5$ & $6.1 \pm 1.4$ & 0.646 & $4.9 \pm 0.9$ & $4.8 \pm 1.3$ & 0.484 \\
\hline Htc; Mean \pm SD & $43.1 \pm 8.8$ & $45.2 \pm 7.7$ & 0.002 & $42.6 \pm 5.9$ & $43.0 \pm 6.2$ & 0.734 & $42.4 \pm 5.7$ & $43.8 \pm 4.7$ & 0.009 \\
\hline Glucose; Mean \pm SD & $66 \pm 14$ & $77 \pm 18$ & 0.000 & $63 \pm 12$ & $71 \pm 14$ & 0.000 & $68 \pm 21$ & $76 \pm 21$ & 0.000 \\
\hline $\mathrm{HCO3}^{-} ;$Mean \pm SD & $23.9 \pm 2.6$ & $22.1 \pm 2.5$ & 0.000 & $22.8 \pm 1.9$ & $21.4 \pm 2.1$ & 0.001 & $24.5 \pm 2.6$ & $22.4 \pm 3.0$ & 0.000 \\
\hline
\end{tabular}

Data are presented as Mean \pm SD, BE: Base Excess, Htc: Hematocrit

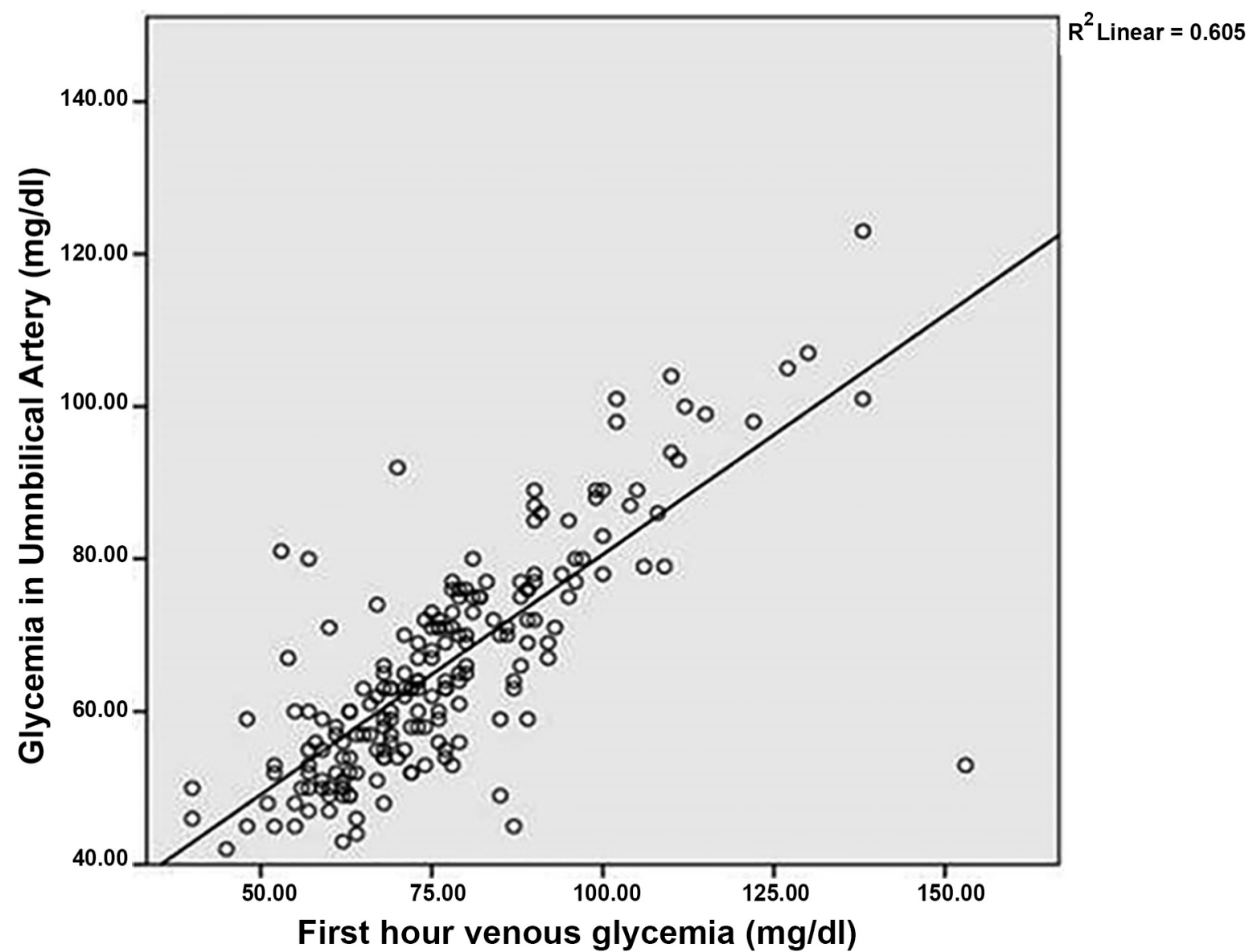

Figure 1. Correlations between glucose levels in arterial cord blood and first-hour glycemia in AGA term infants. 


\subsection{Differences in $U A$ and in $U V$ parameters between AGA term and preterm newborns}

The $\mathrm{pO}_{2}$ was significantly lower in preterm infants than in term infants in the UA and UV (Table 3). BE was significantly lower in preterm than in term infants only in the UA. $\mathrm{K}^{+}$was higher and $\mathrm{Ca}^{++}$was lower in the UA and UV of term infants compared with preterm. $\mathrm{Na}^{+}$was lower in term infants than preterm only in the UA. Glucose levels (Dx) were not different in both groups in either the UA or UV.

\subsection{Relations between UA and UV blood glucose levels and glycaemia in the first hour after birth}

Using a simple linear regression model, significant correlations were found between glycaemia in the UA and UV, and glycaemia in the first hour after birth in all groups. UV and UA glycaemia were significantly associated with venous glycaemia in the first hour after birth ( $\mathrm{p}<0.001$ and $\mathrm{p}=0.008$, respectively).

Table 3. Differences in Umbilical artery and in Umbilical vein parameters between AGA term and preterm newborns

\begin{tabular}{|l|l|l|l|l|l|l|}
\hline \multirow{2}{*}{ Variables } & Umbilical artery & \multicolumn{4}{l|}{ Umbilical vein } \\
\cline { 2 - 7 } & Term & Preterm & p-value & Term & Preterm & p-value \\
\hline $\mathrm{pH}$ & $7.24 \pm 0.29$ & $7,28 \pm 0.08$ & $\mathrm{~ns}$ & $7.34 \pm 0.07$ & $7.29 \pm 0.38$ & $\mathrm{~ns}$ \\
\hline $\mathrm{pCO} 2$ & $51.6 \pm 9.55$ & $53.1 \pm 10.6$ & $\mathrm{~ns}$ & $41.6 \pm 17.5$ & $42.8 \pm 9.3$ & $\mathrm{~ns}$ \\
\hline $\mathrm{pO} 2$ & $24.5 \pm 6.5$ & $22.5 \pm 5.7$ & 0.010 & $36.6 \pm 10.8$ & $32.4 \pm 8.4$ & 0.004 \\
\hline $\mathrm{HCO} 3-$ & $23.3 \pm 4.5$ & $24.5 \pm 2.6$ & $\mathrm{~ns}$ & $21.5 \pm 2.3$ & $22.4 \pm 3$ & $\mathrm{~ns}$ \\
\hline $\mathrm{BE}$ & $-4.0 \pm 2.7$ & $-2.5 \pm 2.6$ & 0.003 & $-3.4 \pm 2.3$ & $-3 \pm 2.6$ & $\mathrm{~ns}$ \\
\hline $\mathrm{Htc}$ & $42.5 \pm 7.2$ & $42.4 \pm 5.7$ & $\mathrm{~ns}$ & $44.1 \pm 6.9$ & $43.8 \pm 4.7$ & $\mathrm{~ns}$ \\
\hline $\mathrm{Na}+$ & $134.15 \pm 5.1$ & $135.7 \pm 3.0$ & 0.000 & $136.0 \pm 4.5$ & $135.4 \pm 2.9$ & $\mathrm{~ns}$ \\
\hline $\mathrm{K}+$ & $6.0 \pm 1.4$ & $4.9 \pm 0.9$ & 0.000 & $5.9 \pm 1.5$ & $4.8 \pm 1.3$ & 0.000 \\
\hline $\mathrm{Ca}++$ & $1.2 \pm 0.4$ & $1.3 \pm 0.4$ & 0.000 & $1.3 \pm 0.1$ & $1.4 \pm 0.1$ & 0.002 \\
\hline Glycaemia & $65.5 \pm 13$ & $68 \pm 21$ & $\mathrm{~ns}$ & $74 \pm 16$ & $76 \pm 21$ & $\mathrm{~ns}$ \\
\hline
\end{tabular}

Data are presented as Mean \pm SD, BE: Base Excess, Htc: Hematocrit

\section{Discussion}

Umbilical cord blood gas analysis at birth is an accepted practice in most hospitals to assess the fetal response to labor (7). Placental status and maternal-fetal metabolic transfer is clinically relevant for caregivers to improve neonatal management. Investigating general metabolic differences between term and preterm umbilical artery and vein is also important in obtaining correct information about fetal status.

\subsection{Differences of $\mathrm{pH}, \mathrm{pCO}, \mathrm{OO}_{2}, \mathrm{BE}, \mathrm{Na}^{+}, \mathrm{K}^{+}, \mathrm{Ca}^{++}$, between $\mathrm{UA}$ and $\mathrm{UV}$ in term and preterm newborns}

The present study, as expected, reported that UV in AGA term infants was more oxygenated than UA. Moreover the UV had a higher $\mathrm{pH}$ than the UA, which indicated adequate intervention of maternal buffer systems in these newborns. Moreover, $\mathrm{Na}^{+}, \mathrm{Ca}^{++}$, and glucose values were higher in the UV than in the UA in AGA term infants, which was likely due to a correct metabolic and nutritive fetus function. Respiratory function was not compromised in the preterm, in which $\mathrm{PO}_{2}$ was significantly higher in the UV than in the UA. Similar to AGA term infants, SGA term infants showed significant differences in $\mathrm{PO}_{2}, \mathrm{PCO}_{2}$, and $\mathrm{pH}$ between the $\mathrm{UV}$ and UA, which indicated metabolic and respiratory compensation by maternal buffer systems. In SGA term infants, any significant difference in $\mathrm{Na}^{+}$and $\mathrm{Ca}^{++}$concentrations were found between the UV and UA, which might be due to immaturity of nutrient uptake of the uterus during the last third of pregnancy $(13,14)$. Furthermore, there was no significant difference in $\mathrm{Na}^{+}$blood concentrations between the UV and UA in preterm infants as well as in SGA term infants. These findings could be related to immaturity of systems, such as the sodium-potassium pump (15). All these data support the hypothesis that fetal health status depends on the respiratory and metabolic ability of placenta, as the crucial interface between mother and fetus. Data also report biochemical parameters of UA and UV in term and in preterm deliveries, without clinical signs of perinatal distress, after delayed cord clamping. Current reference intervals for neonatal umbilical blood gas parameters have been set for early umbilical cord clamping cases (immediately after delivery), which has been the standard of care for many decades. Indeed, delayed cord clamping is the recommended procedure due to the reported benefits for term and preterm infants (16-18). Studies on the effects of delayed cord clamping on cord gas analysis have reported conflicting and non- definitive results $(19,20)$. This study provides a basis for performing research in a larger population to be used as a useful tool to missing samples in high-risk deliveries and in infants subjected to birth asphyxia (21). 


\subsection{Glucose levels in cord blood and in term and preterm newborns at 1 hr of life}

Blood glucose levels among the AGA, SGA, and preterm groups were higher in the UV than in the UA. Therefore, nutritional capacity of the placenta was preserved in all groups. Additionally, there was no difference in glycemic competence between preterm and term infants (both AGA and SGA). This finding indicated an equal degree of maturation of glucose metabolic systems in term and preterm infants (14). In all newborns, neonatal glycemic levels in the first hour of life were directly correlated with those observed in the UA and UV. This result strongly indicates that the UA and UV may be used as indicators of neonatal glycaemia during the first hour of life. This measurement could serve to avoid further painful and stressful blood sampling to the neonate.

\subsection{Study limitations and strengths}

One of the strengths of this study is that we evaluated umbilical cord values in a very homogenous group of women who delivered vaginally or by elective cesarean section, to minimize fetal distress affecting cord blood gas changes. Second, there are no previous references in the literature describing the differences between UA and UV in different clinical conditions such as term AGA and SGA newborns and in preterm. Third, we evaluated the glycaemia in cord blood to establish the relationship with the glycaemia in the first hour of life. The current study represents the most extensive examination of UA and UV blood gas analysis in preterm and in term delivery. The study has the limitation of a small sample size and should be considered as a pilot study.

\section{Conclusions}

UA biochemical parameters significantly differ from UV both in term and in preterm babies. Moreover significant differences exist in UA between term and preterm and in UV between term and preterm. Data suggest that an accurate cord blood gas analysis interpretation, taking into account gestational age, can help clinicians to guide personalized-oriented neonatal care. The predictive values of cord blood glycaemia in both UA and UV will be useful for a tailored management of newborns and to avoid invasive, painful procedures, and to prevent undesirable neonatal hypoglycemia.

\section{Acknowledgments:}

The authors thank the Edanz Group (www.edanzediting.com/ac) for editing a draft of this manuscript.

\section{Conflict of Interest:}

There is no conflict of interest to be declared.

\section{Authors' contributions:}

All authors contributed to this project and article equally. All authors read and approved the final manuscript.

\section{References:}

1) Martin JA, Hamilton BE, Osterman MJ, Curtin SC, Matthews TJ. Births: final data for 2013. National vital statistics reports, 64. Hyattsville, MD: National Center for Health Statistics. 2015: 1e65v

2) Frey HA, Klebanoff MA. The epidemiology, etiology, and costs of preterm birth. Semin Fetal Neonatal Med. 2016; 21(2): 68-73. doi: 10.1016/j.siny.2015.12.011. PMID: 26794420.

3) Finnemore A, Groves A. Physiology of the fetal and transitional circulation. Semin Fetal Neonatal Med. 2015; 20(4): 210-6. doi: 10.1016/j.siny.2015.04.003. PMID: 25921445.

4) Georgieva $\mathrm{A}$, Moulden $\mathrm{M}$, Redman $\mathrm{CW}$. Umbilical cord gases in relation to the neonatal condition: the EveREst plot. Eur J Obstet Gynecol Reprod Biol. 2013; 168(2): 155-60. doi: 10.1016/j.ejogrb.2013.01.003. PMID: 23375905.

5) Kellenberger F, Akladios CY, Sananes N, Gaudineau A, Langer B. The practice of neonatal umbilical blood gas analysis in the "Alsace" regional French perinatal network. J Gynecol Obstet Biol Reprod (Paris). 2016; 45(8): 835-40. doi: 10.1016/j.jgyn.2016.06.006. PMID: 27474088.

6) Øian P. Routines for intrapartum fetal monitoring are important, but why and, more importantly, how are they used? Acta Obstet Gynecol Scand. 2018.

7) Miao H, Mistelbauer G, Karimov A, Alansary A, Davidson A, Lloyd DFA, et al. Placenta Maps: In Utero Placental Health Assessment of the Human Fetus. IEEE Trans Vis Comput Graph. 2017; 23(6): 1612-23. doi: 10.1109/TVCG.2017.2674938. PMID: 28252405.

8) Raghuraman N, Temming LA, Stout MJ, Macones GA, Cahill AG, Tuuli MG. Intrauterine Hyperoxemia and Risk of Neonatal Morbidity. Obstet Gynecol. 2017; 129(4): 676-82. doi: 10.1097/AOG.0000000000001931. PMID: 28277364, PMCID: PMC5559887. 
9) Tsao MF, Chang HW, Chang CH, Cheng CH, Lin HC. Evaluation of Blood Glucose Monitoring System in Screening for Neonatal Hypoglycemia: Tighter Accuracy Standard. J Diabetes Sci Technol. 2017; 11(3): 639-40. doi: 10.1177/1932296816668878. PMID: 27633318, PMCID: PMC5505412.

10) Hussein SM, Salih Y, Rayis DA, Bilal JA, Adam I. Low neonatal blood glucose levels in cesareandelivered term newborns at Khartoum Hospital, Sudan. Diagn Pathol. 2014; 9: 112. doi: 10.1186/17461596-9-112. PMID: 24913607, PMCID: PMC4064508.

11) McDonald SJ, Middleton P, Dowswell T, Morris PS. Effect of timing of umbilical cord clamping of term infants on maternal and neonatal outcomes. Evid Based Child Health. 2014; 9(2): 303-97. doi: 10.1002/ebch.1971. PMID: 25404605.

12) Yeh P, Emary K, Impey L. The relationship between umbilical cord arterial $\mathrm{pH}$ and serious adverse neonatal outcome: analysis of 51,519 consecutive validated samples. BJOG. 2012; (119): 824-31. doi: 10.1111/j.1471-0528.2012.03335.x. PMID: 22571747.

13) Père MC, Etienne M. Nutrient uptake of the uterus during the last third of pregnancy in sows: Effects of litter size, gestation stage and maternal glycemia. Anim Reprod Sci. 2018; 188: 101-13. PMID: 29187294.

14) Tea I, Le Gall G, Küster A, Guignard N, Alexandre-Gouabau MC, Darmaun D, et al. 1H-NMR-based metabolic profiling of maternal and umbilical cord blood indicates altered materno-foetal nutrient exchange in preterm infants. PLoS One. 2012; 7(1): e29947. doi: 10.1371/journal.pone.0029947. PMID: 22291897, PMCID: PMC3264558.

15) Abad C, Vallejos C, De Gregorio N, Díaz P, Chiarello DI, Mendoza M, et al. $\mathrm{Na}^{+}, \mathrm{K}^{+}$-ATPase and $\mathrm{Ca}^{2+}-$ ATPase activities in basal and microvillous syncytiotrophoblast membranes from preeclamptic human term placenta. Hypertens Pregnancy. 2015; 34: 65-79.

16) Nicolaides KH. Committee opinion. Obstet. 2016; 128(654): 1-4.

17) Sanberg PR, Divers R, Mehindru A, Mehindru A, Borlongan CV. Delayed umbilical cord blood clamping: first line of defense against neonatal and age-related disorders. Wulfenia. 2014; 21(6): 243-9. PMID: 25400533, PMCID: PMC4229810.

18) Bhatt S, Alison BJ, Wallace EM, Crossley KJ, Gill AW, Kluckow M, et al. Delaying cord clamping until ventilation onset improves cardiovascular function at birth in preterm lambs. J Physiol. 2013; 591(8): 2113-26. doi: 10.1113/jphysiol.2012.250084. PMID: 23401615, PMCID: PMC3634523.

19) Xodo S, Xodo L, Berghella V. Timing of cord clamping for blood gas analysis is of paramount importance. Acta Obstet Gynecol Scand. 2018; 97(12): 1533. doi: 10.1111/aogs.13445. PMID: 30132787.

20) Tang J, Fullarton R, Samson SL, Chen Y. Delayed cord clamping does not affect umbilical cord blood gas analysis. Arch Gynecol Obstet. 2019; 299(3): 719-724. doi: 10.1007/s00404-019-05048-5. PMID: 30656440 .

21) Ahlberg M, Elvander C, Johansson S, Cnattingius S, Stephansson O. A policy of routine umbilical cord blood gas analysis decreased missing samples from high-risk births. Acta Paediatr. 2017; 106: 43-8. doi: 10.1111/apa.13610. PMID: 27689780. 